\title{
TRANSNACIONALIDADE RECONHECIMENTO DO OUTRO: IMPLICAÇÕES PARA A PRODUÇÃO DO DIREITO
}

\author{
Josemar Soares ${ }^{1}$ \\ Tarcísio Meneghetti ${ }^{2}$
}

\section{Resumo:}

O objetivo do presente artigo é apresentar a ideia de transnacionalidade em relação com a noção hegeliana de reconhecimento e as implicações desta reflexão para a produção do direito, na formalização e efetivação da política jurídica. Para Hegel as leis e instituições são resultados da dialética de reconhecimento entre indivíduos e membros de determinada comunidade. Com isto busca-se demonstrar que o reconhecimento é condição de efetividade das instituições em perspectiva transnacional, sendo o Reconhecimento necessário para efetivação de uma produção do direito funcional em dimensões transnacionais. $\mathrm{O}$ método utilizado é o indutivo, por meio de pesquisa bibliográfica.

Palavras-chave: Transnacionalidade. Reconhecimento. Produção do Direito. Política Jurídica. Estado.

\section{TRANSNATIONALITY AND RECOGNITION OF THE OTHER: IMPLICATIONS FOR THE PRODUCTION OF LAW}

\begin{abstract}
:
The aim of this paper is to present the idea of transnationality in relation to the hegelian notion of recognition and the implications of this reflection for the production of Law, in the formalization and implementation of legal policy. For Hegel, laws and institutions are the result of the dialectic of recognition among individuals members of a particular community. We seek to demonstrate that recognition is a condition of effectiveness of institutions in transnational perspective, and recognition is necessary for the realization of a production of law functional in transnational dimensions. The method used is the inductive, through bibliographic research.
\end{abstract}

Keywords: Transnationality. Recognition. Law Production. Legal Polcy. State.

\section{Introdução}

\footnotetext{
${ }^{1}$ Doutor em Filosofia pela Universidade Federal do Rio Grande do Sul - UFRGS. Mestre em Educação pela Universidade Federal de Santa Maria - UFSM, Mestre em Ciência Jurídica pela Universidade do Vale do Itajaí UNIVALI. Professor no Programa de Pós-Graduação em Ciência Jurídica da UNIVALI. E-mail: jsoares@univali.br

${ }^{2}$ Doutor em Direito pela Universidade do Vale do Itajaí - UNIVALI em programa de Dupla Titulação pela Università Degli Studi di Perugia. Mestre em Direito pela Universidade Federal de Santa Catarina - UFSC. Professor no curso de graduação em Direito da UNIVALI. E-mail: tmeneghetti@ univali.br.
} 
O objetivo do presente artigo é explorar a noção hegeliana de reconhecimento como condição de efetividade de uma produção do direito funcional em dimensões transnacionais.

O problema de pesquisa é: pode a noção hegeliana de reconhecimento contribuir para efetivação de uma produção do direito funcional em dimensões transnacionais?

A partir de noção do Reconhecimento fundamenta-se a ideia de Eticidade em Hegel. A Eticidade é a realização da Ideia de Liberdade no mundo dado, onde a vontade livre encontra a harmonia entre o Indivíduo e as Instituições. É nessa harmonia que se situa a Liberdade hegeliana. Para Hegel o individuo é mitglied, membro de uma comunidade, e na relação intersubjetiva com os demais fundamenta as leis e instituições.

O mundo globalizado, sempre mais marcado pela emergência de fenômenos transnacionais, entre eles as migrações, revela crescente multiculturalismo e pluralismo nas sociedades modernas. A expansiva diversidade, para ser integrada e respeitada dentro de uma lógica comunitária, depende da dialética de reconhecimento.

Esta problemática pode oferecer subsídios de pesquisa à produção do direito, vez que esta se preocupa com o que deve ser o direito, qual caminho seguir, que modificações realizar nas regras vigentes.

Quanto à Metodologia empregada, registra-se que, na Fase de Investigação foi utilizado o Método Indutivo, na Fase de Tratamento de Dados o Método Cartesiano, e, o Relatório dos Resultados expresso na presente Monografia é composto na base lógica Indutiva. (PASOLD, 2008)

As citações de Hegel utilizam as fontes em alemão e traduções nacionais de Paulo Meneses.

\section{DESENVOLVIMENTO}

\section{Transnacionalidade, Estado e Sociedade: premissas para a produção do direito}

Inicia-se este estudo esboçando a relação entre Estado e dialéticas entre indivíduos.

O positivismo jurídico, em suas diversas correntes, sobretudo a kelseniana, parte da ideia de que o Estado é uma entidade abstrata concebida para resolver os vínculos normativos a partir de indivíduos atomizados, conforme argumenta Heller: 
Se a unidade do Estado só nos fosse dada realmente 'pela ciência jurídica' (Kelsen, Staatsbegriff, p. 8), seria evidentemente inconcebível como realidade. A união normativa interindividual que se dá na ordem jurídica entre vontades individuais que na realidade estão dissociadas, não basta para explicar a existência do Estado. A unificação volitiva, em virtude da qual nasce no indivíduo a vontade eficaz para o coletivo, produz-se, sobretudo, como um processo de ordenação e acomodação dentro de cada indivíduo, que se vê pressionado em cada momento pela conveniência social e em quem a educação de numerosas gerações gerou o estado habitual de uma consciência de nós mais ou menos clara e firme. (HELLER, 1968, p. 279).

A argumentação meramente jurídica de justificação do Estado e sua normatividade é insuficiente, pois a obediência dos indivíduos às normas impostas pelo Estado não se pode explicar recorrendo apenas à termos jurídicos. $\mathrm{O}$ fato de o indivíduo harmonizar-se com os demais e aceitar viver conforme regras sociais mais ou menos claras e estabelecidas está intimamente vinculada à educação de gerações visando a formação de um indivíduo socializado e compenetrado nos meios sociais. Não é simplesmente por ser regra obrigatória que o indivíduo obedece ao Estado, mas por ser educado socialmente a se adaptar às normas sociais, inclusive aquelas emanadas pelo Estado. De certa forma a educação das instituições intermediárias, como família, escola, sociedade civil, entre outras, prepara a consciência individual para aceitar a submissão ao poder estatal.

O Estado, ainda que entendido em acepção meramente jusnormativa, depende primeiramente da natureza social do homem, pois as normas abstratas formuladas para regulamentar o corpo de cidadãos não é a razão de vínculo entre os cidadãos, mas um instrumento para organização de uma dada Sociedade já construída historicamente, culturalmente, socialmente. Primeiro determinadas pessoas passam a conviver e seguir certas regras, costumes, e apenas depois tais regras passam a se tornar mais complexas e abstratas. Em algumas Sociedades o nível de complexidade alcança patamares tão elevados que requerse a instituição do Estado. ${ }^{3}$ Mas tal instituição, como lembra Sacco, não é obrigatória nem presente na maioria das Sociedades humanas.

\footnotetext{
3 "A instituição estatal justifica-se, pois, pelo fato de que em uma determinada etapa da divisão do trabalho e do intercâmbio social a certeza de sentido e de execução do direito tornam-se necessárias ao Estado. Do mesmo modo que o aumento do tráfego urbano até um certo grau reclama uma regulação do mesmo, e inclusive órgãos de polícia de tráfego, assim também o desenvolvimento da civilização torna precisa uma organização estatal cada vez mais diferenciada para o estabelecimento, aplicação e execução do direito. A instituição do Estado aparece, deste modo, justificada pelo fato de ser uma organização de segurança jurídica, e só por isso." (HELLER, 1968, p. 267). Fundamental a ênfase na expressão 'segurança jurídica', pois o Estado é a instituição
} 
O contrato social e em geral a maior parte das doutrinas políticas modernas, lembra Hegel, partem do pressuposto que o homem existe primeiramente enquanto indivíduo e só depois enquanto ser político e intersubjetivo. Mas esta visão não resiste à realidade. O homem é, desde o nascimento, um ser social.

Também León Duguit (1922) lembra que a ideia de indivíduo atomizado não existe na realidade e não pode ser comprovada empiricamente por nenhum método.

Não é apenas o conceito de Estado que deriva da natureza social do homem, mas também o de comunidade, de nação, de povo, de tribo, de família, e, podemos alargar, ao de qualquer instituição moderna, como a empresa e os partidos políticos. Todas estas instituições seriam conexas à ideia de dialética do reconhecimento, para utilizar terminologia hegeliana. $\mathrm{O}$ fundamento das instituições e da vida comunitária (incluindo o Estado) está na natureza social do ser humano. ${ }^{4}$

Com isso não se pretende dizer que o homem é primeiramente um ser coletivo e só depois individual. É evidente que cada ser humano existe em si mesmo. O que busca-se enfatizar é que o ser humano é um ente relacional, que vive a partir de relações intersubjetivas. Isto é bastante diferente de afirmar que o coletivo é superior ao indivíduo. Mesmo o livre mercado, instituição que consagra a necessidade egoísta (no sentido positivo

\footnotetext{
que põe as regras concebidas pela sociedade, bem como as regras que permitem a alteração das anteriores, ou seja, cria as condições jurídicas para que as forças internas possam agir sem recorrer aos meios violentos. Se há regras que explicam o funcionamento interno daquela sociedade haverá também a estipulação dos meios de modificar tais regras, não aceitando que determinados grupos tentem impor suas vontades por violência física, bem como se defina limites mínimos de proteção à sociedade em geral. A instituição do Estado (prevalecendo sobre outras instituições sociais, como a família, as corporações, etc.) parece ser resultado da progressiva complexificação das sociedades modernas.

${ }^{4}$ Importante neste ponto acrescentar o argumento de Heller, demonstrando que o Estado expressa sempre a realidade social e cultural de seu povo, justificando assim a precedência da Sociedade em relação ao Estado: O Estado, porém, não pode ser concebido nem como sociedade nem como comunidade exclusivamente. A sua lei decisiva de formação é certamente a organização; pois não só por meio dela cresce consideravelmente o seu valor de efetividade social, mas sem ela não tem, em geral, existência. Mas, por outra parte, não deve ser considerada em nenhum caso como mero produto da técnica organizadora, como acontece na sociedade anônima; o indivíduo aparece sempre inserido no Estado, voluntária e involuntariamente, segundo zonas vitalmente importantes do seu ser. A organização da sociedade anônima pode ser completamente independente da maneira de ser dos acionistas. Em compensação, a organização estatal penetra profundamente na vida pessoal do homem formando assim o seu ser, ao mesmo tempo em que, por seu lado, os membros influem decisivamente sobre ela. Por isso dizemos que o Estado é uma forma organizada de vida cuja Constituição se caracteriza, não só pela conduta normada e juridicamente organizada dos seus membros, mas ainda pela conduta não normada, embora normalizada, dos mesmos". HELLER, 1968, p. 297. Nas sociedades anônimas é possível que suas culturas e atividades apresentem estilos totalmente diversos à personalidade dos seus acionistas, pois não necessariamente há vínculo direto entre eles. Tal cisão existencial é impossível no Estado, pois este ao mesmo tempo em que imprime o modo de viver aos indivíduos recebe destes as condutas que tendem a ser normalizadas e normatizadas futuramente. O Estado expressa a sociedade e a sociedade expressa o Estado, embora sejam conceitos distintos.
} 
de buscar a própria satisfação e felicidade e não de exploração do outro) do homem, depende das relações intersubjetivas para ser efetivado. (HEGEL, 1982).

Há a natureza individual de cada pessoa, mas tal natureza já é constituída como aberta às múltiplas e infinitas relações intersubjetivas com o mundo, aquilo que podemos definir como díades.

É certo, portanto, que o Estado origina-se da natureza social, intersubjetiva, do homem. Mas também a família, a corporação medieval, as ordens de cavalarias, as sociedades empresárias contemporâneas, as tribos, clãs, e mesmo as organizações criminosas, nascem da natureza social do homem. Todas estas instituições sociais, de modo consciente ou não, carregam a ideia de que o homem é um ser social, que deseja conviver com o outro para assim realizar determinado fim comum. A vida em Sociedade permite alcançar resultados de bemestar superiores àqueles disponibilizados ao indivíduo atomizado (que até pode ser teorizado mas dificilmente constatado empiricamente). ${ }^{5}$

A opção pelo Estado, seguindo a teoria de Heller, parece ser consequência da própria história moderna ocidental, pois em determinados territórios conviviam diversas etnias, culturas religiosas e inclusive de línguas distintas, e que ainda precisavam se defender militarmente de agrupamentos humanos externos. Como, por exemplo, reunir sob a mesma bandeira a diversidade de povos, línguas e culturas que conviviam no mesmo espaço onde hoje é a Espanha, a França ou a Itália ${ }^{6}$ O Estado, dessa forma, surgiu como opção viável e inteligente para tentar resolver tal paradigma.

O Estado, para Heller, é uma unidade de vontade e de ação, resultante da pluralidade de vontades e não subordinada a nenhuma outra unidade política decisória superior. Assim, sempre que se fala em soberania do Estado, se vincula, de alguma forma, a soberania do povo. A unificação das vontades se dá pelo princípio majoritário e pela representação, meios técnicos que possibilitam ao povo, como unidade, dominar ao povo como pluralidade, permitindo, assim, que o povo seja o sujeito da soberania. (BERCOVICI, 2007, p. 337).

\footnotetext{
${ }^{5}$ A Sociedade, para alcançar dimensões mais qualitativas nas relações e instituições, exige um comprometimento dos indivíduos tendo em vista a fraternidade. Ver SILVA, Ildete Regina Vale da ; SOUZA, Maria Cláudia da Silva Antunes de. Fraternidade e Sustentabilidade: Conpedi Law Review, v. 4, p. 330-349, 2018.

${ }^{6}$ Adverte Habermas: "A concepção republicana naturalmente não exclui que comunidades étnicas possam conferir-se uma constituição democrática e possam se estabelecer como Estados soberanos, na medida em que essa independência se legitime a partir do direito individual de cada cidadão a viver em liberdade, de acordo com as leis. Porém, via de regra, os Estados nacionais não se desenvolvem de modo pacífico, a partir de etnias individuais, que vivem de forma isolada. Com muito maior frequência eles se expandem para regiões, tribos, subculturas e comunidades linguísticas e religiosas vizinhas. Os novos Estados nacionais surgem geralmente à custa de 'povos inferiores' assimilados, oprimidos ou marginalizados. A formação de Estados nacionais sob o signo do etnonacionalismo foi quase sempre acompanhada de sangrentos rituais de limpeza e sempre submeteu novas minorias a novas repressões". (HABERMAS, 2004, p. 168).
} 
O Estado é a unidade na pluralidade, no sentido de que dá forma e ordem às divergências internas, às contradições que permeiam a pluralidade real na vida moderna. Sem o Estado há inúmeras instituições disputando por espaço na vida social, com o Estado há a possibilidade da totalidade de indivíduos, ainda que de realidades distintas, dialogarem tendo em vista o bem comum. É a unidade que ordena a pluralidade de atores.

A modernidade monopolizou toda a produção e aplicação jurídica na instituição do Estado, simplificando a complexidade da vida social, pois ignora a realidade social como sendo de natureza pluralista. O monismo estatal hoje é atacado tanto de cima como de baixo. De cima pelas forças transnacionais e globalistas, que defendem a realidade supranacional e supraestatal, no sentido de que o Estado-Nação já não consegue ser eficiente como regulamentador das relações cada vez mais difusas e transnacionais no século XXI. Os que atacam o monismo estatal de cima citam o comércio internacional, o meio ambiente, a proteção aos direitos humanos e o combato ao crime organizado como exemplos de matérias em que o Estado-Nação parece incapaz de conferir soluções eficazes. Já os que atacam o monismo estatal de baixo alertam para o fato de que monismo simplificou a realidade social, padronizando as relações sociais, econômicas e jurídicas apenas no viés liberal-burguês, marginalizando parcelas consideráveis da Sociedade a não se verem refletidas na realidade estatal.

É necessário salientar que o pluralismo jurídico é compatível com a Constituição, pois reconhecer a diversidade de ordenamentos jurídicos, conforme o entendimento de Santi Romano, não significa, necessariamente, ser contrário à submissão à Constituição como unidade que ordena a pluralidade. A Constituição não é apenas expressão da realidade estatal, mas da própria Sociedade, sendo assim a própria Constituição tem poder para reconhecer a pluralidade de instâncias que permeiam a diversidade social, conferindo a esta diversidade a competência para regulamentarem a si mesmas. O reconhecimento de tais realidades na Constituição permitiria inclusive a criação de métodos de resolução de conflitos entre tais instâncias. A Constituição, documento oficial que integra e harmoniza as reivindicações das 
várias camadas sociais, poderia se tornar a pedra fundamental da qual emanam diversos ordenamentos jurídicos dentro da própria nação. ${ }^{7}$ (LUNO, 2012, p. 22-24).

O direito moderno e liberal encontra sérias dificuldades para lidar com o pluralismo, tendo em vista que reduz quase todas as dialéticas sociais àquela Indivíduo-Estado, ignorando as instituições intermediárias. O ser humano é indivíduo, mas também é membro de diversos grupos sociais, além do Estado. Um dos grandes desafios para a Ciência Jurídica contemporânea é justamente conseguir abarcar a pluralidade de relações humanas em um ordenamento ou conjunto de ordenamentos jurídicos em harmonia.

A situação se torna mais densa quando se enfrenta a problemática da transnacionalidade na contemporaneidade, esta sempre mais fragmentada, menos dependente do centralismo na instituição do Estado. ${ }^{8}$

É possível vislumbrar na contemporaneidade a emergência de um certo espaço jurídico global, uma arena de interesses, conflitos, que recebem a participação de múltiplos atores, dos Estados nacionais a empresas, passando por organizações não-governamentais, indivíduos, instituições supranacionais como ONU, UNESCO, entre outras. O pluralismo abordado até aqui se reforça na transnacionalidade.

O que é fundamental destacar é que a sociedade contemporânea apresenta realidade sempre mais transnacional, uma série de fenômenos comerciais, culturais, sociais, que se desenvolvem para além das fronteiras estatais, mas que condicionam a realidade estatal. Se, como já visto com Perez-Luño e outros, é difícil convergir a pluralidade moderna à lógica estatalista constitucional, o desafio de fazer convergir o pluralismo transnacional a uma ordem jurídica transnacional exige da ciência jurídica atividade racional ainda mais intensa. Neste sentido o presente artigo apresenta a dialética de reconhecimento como movimento essencial para melhor compreensão do pluralismo, sobretudo na dimensão transnacional.

\footnotetext{
${ }^{7}$ LUNO, Antonio Henrique Pérez. Perspectivas e Tendências Atuais do Estado Constitucional. Tradução de José Luis Bolzan de Morais e Valéria Ribas do Nascimento. Porto Alegre: Livraria do Advogado, 2012. p. 2224.

${ }^{8}$ Para aprofundamentos sobre o conceito de transnacionalidade ver: OLIVIERO, Maurizio; CRUZ, Paulo Marcio. Reflexões sobre o direito transnacional, Revista Novos Estudos Jurídicos, v. 17, n. 1, p. 18-28, jan-abr 2012; STAFFEN, Márcio Ricardo. Hegemonia e Direito Transnacional?, Revista Novos Estudos Jurídicos, v. 20, n.3, p. p. 1166-1187; SOARES, Josemar; CRUZ, Paulo Marcio. Critério Ético e Sustentabilidade na Sociedade Pós-Moderna: Impactos nas dimensões econômicas, transnacionais e jurídicas. Revista Novos Estudos Jurídicos, v. 17, n. 3, p. 401-418, set-dez 2012.
} 
A dificuldade de tornar o direito existente sempre mais próximo daquilo que anseia cada sociedade é ponto de partida para as pesquisas sobre produção do direito, área da qual se encarrega a política jurídica. No próximo tópico aborda-se a política jurídica e seus principais fundamentos.

\section{PRODUÇÃO DIREITO E POLÍTICA JURÍDICA}

A Política Jurídica, ou Política do Direito, é a disciplina que estuda o Direito que deve ser e como deva ser em contraponto a dogmática jurídica que estuda a interpretação e aplicação do Direito vigente. (MELO, 2000, p. 77).

Essa disciplina visa alcançar o Direito desejado pela Sociedade, pautando-se, assim, nos critérios de Ética, Justiça, Legitimidade e Utilidade. Para alcançar um Direito que atenda a esses critérios, é necessário a propositura de novas normas, adequação daquelas existentes e a reconceituação do próprio Direito e de seus núcleos. (CAVEDON, 2011, p. 65).

Cabe à Política Jurídica a percepção e apreensão dos desejos e necessidades da Sociedade, introduzindo no sistema jurídico elementos valorativos que foram afastados pela dogmática jurídica em nome da segurança. (MELHO, 2000, p. 77).

Para a Dogmática Jurídica é válida toda norma positivada, desde que autorizada por norma superior, elaborada por autoridade competente e com fiel observância aos ritos do processo legislativo. Porém, para a Política Jurídica, a validade de uma norma não pode ser extraída apenas do seu aspecto formal, mas deve considerar também a legitimidade ética de seu conteúdo e de seus fins. (MELO, 1994, p. 87-88).

Sendo assim, a Política do Direito busca, tanto em fontes formais ou informais, as representações jurídicas do imaginário social que tenha legitimidade na ética, nos princípios de liberdade e igualdade e na estética da convivência humana. (MELO, 1994, p. 131).

A Política do Direito deve buscar um Direito que por meio de suas normas crie um ambiente em que se permite a estética do conviver, que permite aos homens um mínimo de auto-respeito e reconhecimento recíproco da dignidade de cada um, tanto no relacionamento entre si quanto no relacionamento com o ambiente, com o mundo. (MELO, 1994, p. 63).

A Estética aparece como forma de se buscar o mais belo do homem, da norma, do Direito. O Esteticismo é uma expressão usada para significar uma atitude que dê importância 
superior aos valores estéticos nos fatos da vida. O homem ético é aquele inconformado com o injusto e com o incorreto, o homem estético é não pode conformar-se com o feio produzido pelo injusto e pelo incorreto. (MELO, 1994, p. 62). Pergunta Osvaldo Ferreira de Melo (1994, p. 62):

Se a grande função da arte é propiciar prazer espiritual, que prazer maior para o ser humano sensível do que o bem-conviver, a comunicação aberta, o sentir-se aceito na diversidade, e descobrir-se com as condições psicológicas e culturais de aceitar o pensar do outro?

A arte de viver é uma constante colocação da estética na convivência, é criar um ambiente favorável para o desenvolvimento da tolerância, do pluralismo de ideias, da aceitação dos valores dos outros. A democracia, na sua mais elevada acepção, quando transcende simples arranjos políticos, tem sua estética própria. (MELO, 1994, p. 62).

Para a Política Jurídica, é necessário rever as fontes tradicionais do Direito, para privilegiar aquelas que realmente sustentem um Direito novo, desejável, criativo, libertador, racional e que cumpra sua função de responder aos anseios sociais. (MELO, 1994, p. 131).

Os objetivos da ação político-jurídica visam à desconstrução de paradigmas que negam ou impedem a criatividade como um agir permanente, assegurando, assim, a valorização do ser humano e a dignidade de tratamento dos homens entre si e com a natureza. (MELO, 1994, p. 132).

Na obra Temas Atuais de Política do Direito,Melo destaca alguns pontos acerca da importância do estudo da Política Jurídica, primeiramente destacando a própria relação entre Política e Direito, afirmando que é possível e desejável uma teorização sobre a conciliação entre Política e Direito, entendidas ambas as categorias em um sentido ético-social e identificados os respectivos conceitos, tanto quanto possível, com a ideia do justo e do legitimamente necessário, ou seja, do socialmente útil. (MELO, 1998, p. 14).

Em decorrência dessa reciprocidade, o Direito necessita da Política para continuamente renovar-se nas fontes da legitimação, e a Política necessita do Direito para objetivar as reivindicações sociais legítimas, ou seja, propor um sistema de categorias, conceitos, princípios e normas capazes de assegurar não só relações econômicas mais justas, mas também o alcance de um ambiente social realmente ético e estimulador das práticas solidárias. (MELO, 1998, p. 14). 
As teorias para fundamentar as técnicas de construção, interpretação e aplicação da norma preocupam-se prioritariamente com a lógica ou outras formalidades, descompromissadas com o conteúdo ético que é próprio da natureza do Direito, sendo usadas indiscriminadamente para desmandos autoritários e atendimento a reivindicações sociais. Já a Política do Direito, arquitetada sobre critérios de prudência e possibilidades e fundamentada em padrões éticos, estará a serviço de um devir desejável e realizável, como proposta criativa aos desafios que forem surgindo. (MELO, 1998, p. 14).

A Política Jurídica não é descritiva, é prescritiva, comprometida com as necessidades e interesses sociais, e sempre interessada nos conhecimentos que lhe podem oferecer a Ciência Jurídica, a Filosofia do Direito e a Sociologia Jurídica, na busca dos aportes teóricos necessários à compreensão dos fenômenos jurídico e social. (MELO, 1998, p. 14).

Importante o destaque de que a Política Jurídica não é pura teoria, mas é voltada para o agir. Toda ação corretiva e criativa recairá sobre o sistema normativo vigente, influindo na sua permanente adequação e aperfeiçoamento. (MELO, 1998, p. 14).

$\mathrm{Na}$ sequência apresentam-se elementos da filosofia política hegeliana, uma das primeiras abordagens modernas a tentar enfrentar a questão da pluralidade de relações humanas internas ao Estado. Daí que a análise do pensamento hegeliano pode oferecer interessantes subsídios para compreender a situação contemporânea. A ideia é oferecer subsídios para melhor efetivação da produção do direito nos tempos atuais.

\section{Reconhecimento, Transnacionalidade e Sociedade Sustentável}

Para compreender a posição da filosofia política hegeliana dentro da complexa sistemática do autor é preciso fazer algumas considerações acerca da Filosofia do Espírito dentro da Enclicopédia das Ciências Filosóficas, obra em três volumes em que Hegel apresenta sistematica a relação entre cada um dos conceitos por ele explorados nas demais obras. Na Enciclopédia a filosofia política está inserida no terceiro momento, a da Filosofia do Espírito, depois da Ciência da Lógica e da Filosofia da Natureza.

A Liberdade é uma possibilidade, que pode vir a se tornar efetivada. É responsabilidade do Indivíduo realizar da Liberdade em si mesmo e no mundo. Não basta ao espírito ser livre em conceito ou em possibilidade, é necessário que o seja de modo efetivo no mundo. 
Também é substancial compreender o início da citação, quando se afirma que a Liberdade passa pela autonomia em relação ao Outro, mas que essa autonomia não é fugir do Outro, mas uma vitória no Outro. Isso será demasiadamente importante para se compreender a exposição de todo este trabalho. A relação do Eu com o Outro deve ser uma relação de independência para ambos, porém sem a exterminação de uma das partes. O extermínio do Outro não é Liberdade, mas fuga do Outro. E essa mensagem Hegel já expôs de modo decisivo e emblemático na célebre dialética entre senhor e escravo na Fenomenologia do Espírito.

A intersubjetividade é essencial para a Filosofia do Espírito de Hegel. E isso pode ser extraído da parte final da citação acima. A Liberdade se faz quando o espírito liberta-se de todas as formas que não são próprias ao conceito do espírito. Essas formas precisam ser transformadas em uma efetividade perfeitamente apropriada ao conceito do espírito. Isso se tornará mais assimilável ao longo do trabalho, quando for apresentado que a Liberdade não passa pela eliminação das Instituições, mas na transformação dessas em algo apropriado ao conceito do espírito. Tal discussão é o cerne da presente pesquisa.

Em síntese, o espírito consiste numa dialética de intersubjetividade do Indivíduo com a Natureza e o mundo. O homem nasce em um mundo que é um Outro, e depois se vê rodeado de outros seres-Outros, outros homens. Por fim, há as todas as construções racionais humanas, como o direito, a moral, as Instituições, as ciências e assim por diante. Tudo isso é um Outro, que me provoca a agir de um determinado modo. Porém, todas essas construções refletem também a vontade humana em transformar o mundo natural em um mundo humano, e isso é algo fundamental quando se pensa em Liberdade diante do mundo.

Não se pode pensar a Liberdade em Hegel apenas na Liberdade individual, na minha Liberdade, na tua Liberdade. Antes disso, a Liberdade é uma ideia que se engendra no espírito, e o espírito envolve tanto os particulares, os Indivíduos singulares, como a relação entre eles, nas formas da família, da sociedade civil, do Estado, e inclusive na relação de todos eles com o mundo. Trata-se, portanto, de uma Liberdade em sentido bastante amplo.

A partir do momento que o espírito produz o mundo à sua reflexão, atualiza não apenas o mundo, mas a si mesmo. Esse trabalho de criação do mundo produz a efetivação da ideia de Liberdade num movimento gradual consoante ao de autorrevelação do espírito. 
No espírito subjetivo temos a divisão em antropologia, fenomenologia, estudada mais profundamente na obra Fenomenologia do Espírito (2005) e psicologia. Aqui se analisa o Indivíduo enquanto consciência, enquanto singularidade em seus aspectos internos e na sua relação com os demais. Trata-se de um estudo eminentemente existencial e, por vezes, inclusive psicológico. O espírito nesse momento é subjetivo justamente por explorar os aspectos da subjetividade humana, a qual se apresenta em cada consciência, porém em cada uma de modo diferente. Dois sujeitos possuem dilemas, complexidades e aspectos internos sempre distintos.

Depois da realidade singular do homem passa-se ao estudo da realidade objetiva e concreta, que é o mundo externo. Este trabalho se concentrará no estudo dessa parte, pois é aqui que se fazem presentes as relações sociais, jurídicas, políticas, morais entre as pessoas. Com efeito, é nesse momento que se pode estudar a relação entre o Indivíduo e as Instituições. O espírito é então objetivo porque explora questões que envolvem todos os Indivíduos da mesma maneira, numa universalidade. É na universalidade que se estuda o direito, a ética e a política, pois essas dimensões são criadas visando o universal, ainda que esse deva conter o particular. O espírito objetivo se desdobra no direito abstrato, na moralidade e na eticidade, Instituições que serão analisadas mais profundamente neste trabalho. Também o direito integra o mundo da eticidade.

Pode-se dizer que numa abordagem hegeliana o Direito surge como fenomenologia porque é emanado pelos costumes e valores reconhecidos por determinada Sociedade. As normas e instituições jurídicas não são regras absolutas, mas resultados do percurso histórico. O movimento de negação das regras e instituições, entretanto, permitira visualizar a Ideia que as faz movimentar, ou seja, a própria lógica jurídica que subsistiria subterraneamente ao movimento concreto do Direito.

Observa-se agora abordagem conferida na obra Linhas Fundamentais da Filosofia do Direito.

Hegel (1982, p. 292) inicia a exposição da Eticidade no § 142:

A eticidade é a ideia da liberdade, enquanto Bem vivente, que tem na autoconsciência seu saber, seu querer, e pelo agir dessa, sua efetividade, assim como essa tem, no ser ético, seu fundamento sendo em si e para si e seu fim motor, - [a eticidade é] o conceito da liberdade que se tornou mundo presente e natureza da autoconsciência. 
Por autoconsciência entende-se aqui a mesma figura da consciência de si, já indicada na Fenomenologia do Espírito. Somente por meio da consciência de si é possível elevar um projeto social como a eticidade.

Muitas interpretações foram feitas da Filosofia do Direito de Hegel, da liberal ao comunismo, do enaltecimento do indivíduo ao absolutismo estatal. A eticidade, conforme exposto no conceito do $§ 142$, não se baseia nesta fragmentação.

A eticidade resultada do saber e do querer da consciência de si, depois de superar diversos momentos, a se iniciar pela dialética do reconhecimento. A eticidade é o conceito da liberdade que se tornou mundo presente e natureza da consciência de si, isto é, a própria ideia de Liberdade realizada, de que de tal forma se tornou uma segunda natureza da consciência de si.

O ser ético, dessa forma, não é externo e coercitivo à consciência, mas seu próprio conteúdo, de tal forma que as instituições e leis que derivarem daquela comunidade e Estado não são opressoras contra seus membros, mas a manifestação da vontade dos indivíduos.

Isto não significa que Hegel autoriza considerar qualquer Estado como livre e manifestação da eticidade. A eticidade é um processo espiritual e histórico, e que nasce apenas de uma série de dialéticas fenomenológicas e históricas efetuadas pelo indivíduo e pela humanidade, de tal forma que para Hegel seria possível somente na modernidade ${ }^{9}$.

O mundo ético é harmônico e dialético, onde uma série de interesses (família, sociedade civil, Estado, indivíduo, etc.) coexistem, às vezes de modo conflituoso, mas sem jamais ameaçar a existência do ser ético, ou da eticidade em si.

A eticidade seria aquele momento de convivência social onde os indivíduos sabem ser membros efetivos de uma totalidade maior, seja ela o Estado ou a comunidade em geral, e respeita a Constituição e as normas emanadas pelo Poder Público não por atitude de obrigação mas por vontade livre.

Por outro lado, a substância ética, suas leis e suas potências, não passam, para o sujeito, como algo de estranho, mas, tem o testemunho de constituir em si mesma sua própria essência, onde tem o seu sentimento e nele vive como um elemento não diferente de si. Trata-se de uma relação imediata, que é mais idêntica que na fé e na confiança. (HEGEL, 1982, p. 295).

\footnotetext{
${ }^{9}$ Embora possua relação, a eticidade da Filosofia do Direito não é a mesma eticidade da Fenomenologia do Espírito, que se refere ao mundo grego. O vínculo entre ambos é a Harmonia, imediata no mundo grego e mediatizada na modernidade.
}

Revista Brasileira de Filosofia do Direito | e-ISSN: 2526-012X | Belém | v. 5 | n. 2 | p. 142 - 158 | Jul/Dez. 2019. 
Entretanto, mais importante que o respeito em si às instituições e normas, que parecem ser mais efeito que causa, é o processo de reconhecimento mútuo, já realizado pelas consciências de si. O indivíduo não agride o outro e as instituições porque reconhece o outro e as instituições como ele próprio, pois todos são membros de uma totalidade orgânica, logo agredir o outro é agredir a si mesmo. Objetivamente falando o homicídio não é o ato de matar apenas um indivíduo, mas a própria ideia de humanidade, e o representante eleito que se aproveita de seu cargo para praticar atos ligados à corrupção não está apenas enriquecendo ilicitamente, mas agredindo o ser ético do Estado. Entretanto, tais preocupações e discernimentos não perpassam a consciência do sujeito que pratica tais atos.

Não se reputa aqui que o sujeito precisa saber discernir as ideias de reconhecimento e ser ético. Na verdade, se tal ideia estivesse enraizada em seu ser, de modo inconsciente ele se negaria a praticar tais atos. O problema não é a inconsciência da dialética do reconhecimento, mas a sua falência ou até inexistência nos dias atuais.

O problema é existencial e, portanto, anterior à esfera jurídica, política e social, anterior inclusive à esfera ética/moral.

$\mathrm{Na}$ dialética do reconhecimento hegeliana a consciência precisa sair de si e reconhecer o outro como a si mesmo. Como já salientado, Hegel substituiu o amor pela luta/conflito, portanto não se trata de exigir das pessoas o amor, o sentimento genuíno pela humanidade, como queria Fromm, e como foi tão salientada na filosofia cristã, mas apenas um sentimento de respeito mútuo pelo outro, de reconhecimento de seu valor e humanidade, de entender que o outro é igual a ele mesmo, então ambos membros de um mesmo projeto social maior. Amor seria uma etapa ainda mais evoluída desse processo.

O que se coloca em questão é se uma consciência que não reconhece o outro pode reconhecer a si mesma. Como afirmava Hegel, reconhecimento é necessariamente mútuo. Ser pessoa implica em ser reconhecido por outros como pessoa, da mesma forma que ser proprietário de um bem implica em reconhecer o outro também como proprietário de um bem. Não há real dicotomia entre direitos e deveres. Exercer o direito responsabiliza o sujeito no dever de respeitar o direito alheio. A partir desta ótica é possível pensar uma Sociedade Sustentável, na qual reconhecimento condiciona a busca por qualidade de vida para todos os envolvidos, inclusive em dimensões transnacionais.

Trazendo a discussão sobre pluralismo e transnacionalidade verifica-se a contribuição do argumento do reconhecimento como compreensão das dinâmicas intersubjetivas em 
espaços transnacionais. Se o Estado moderno tentou fazer convergir os diversos atores (sujeitos e instituições) para dentro da sua órbita, deve agora a ciência jurídica pensar a transnacionalidade com nova perspectiva de racionalidade, vez que muitos fenômenos se manifestam para além do Estado (não são reconhecidos nem reconhecem efetivamente a exclusividade estatal como centro produtor do direito. Ou seja, é preciso novo processo de reconhecimento dos indivíduos no interior do Estado e dos novos fenômenos transnacionais, de modo que se sintam membros efetivos destas dimensões. A instituição encontra permanência e efetividade histórica na medida em que os indivíduos agem como membros, reconhecem suas normas, tal como explicitado por Hegel. O indivíduo como membro do Estado, como membro de uma sociedade civil global, das corporações, de um mercado de alcance transnacional, um indivíduo que por ser membro se sinta responsável efetivo perante os direitos ambientes, humanos, sociais. O reconhecimento hoje precisa ser feito na dimensão global, diante do pluralismo de fenômenos transnacionais.

\section{Considerações finais}

Para Hegel as instituições políticas e jurídicas surgem da relação dialética de reconhecimento entre os indivíduos membros de cada comunidade. É do processo de reconhecimento do Eu no outro que emanam a família, as instituições da sociedade civil, como o mercado, o Estado, e as normas jurídicas como um todo.

A comunidade ordenada é aquela em que os interesses individuais estão em harmonia com as necessidades coletivas, gerando o bem comum, benefícios universais aos membros envolvidos. Para Hegel este seria seria o sistema da vida ética, da eticidade.

$\mathrm{Na}$ eticidade as relações intersubjetivas superam a dicotomia subjetivo-objetivo e se tornam querer e saber da própria consciência de si, ou seja, as leis éticas se tornam uma segunda natureza, de tal forma que viver conforme as instituições de sua Sociedade e Estado não são uma forma de abuso, mas o reflexo da própria vontade.

O referente acima pode auxiliar na discussão da intersubjetividade no direito contemporâneo, pois cada regulamentação jurídica nasce da necessidade de ordenar determinada relação, seja entre sujeitos, seja entre sujeitos e coisas. É o momento, portanto, de repensar o direito de matriz individualista, conforme preconizou a ideologia liberal- 
moderna, pois o fundamento da norma não parece ser o indivíduo isolado, atomicista, inexistente na realidade natural, mas a relação entre dois polos. Sendo o ser humano naturalmente sociável o direito regulamentaria sua relação com os demais e com os objetos em geral, sob o prisma do bem comum, daquilo que é universalmente válido e benéfico para todos.

Desse modo a reflexão hegeliana se torna importante na compreensão das dinâmicas de como é possível construir uma produção do direito em dimensões transnacionais, partindo da ideia de que a Eticidade se elabora na perspectiva de que o indivíduo busca reconhecer o outro visando o bem comum, aquilo que é universal e objetivo. Daí é possível a projeção de instituições, regras jurídicas em dimensões transnacionais, utilizando a dialética de reconhecimento para além das fronteiras nacionais.

A produção do direito, embora originada como estudo voltado sobretudo ao direito nacional e estatal, hoje possui ferramentas para extender suas pesquisas ao âmbito do direito transnacional, e a dialética do reconhecimento aqui surge como alternativa de fundamento, vez que categorias como nação, povo, etnia, entre outras, parecem insuficientes para justificar o direito transnacional.

\section{Referências das fontes citadas}

BERCOVICI, Gilberto. As possibilidades de uma Teoria do Estado. In LIMA, Martonio Mont ' Alverne et ALBUQUERQUE, Paulo Antônio de Menezes. (organizadores). Democracia, Direito e Política: estudos internacionais em homenagem a Friedrich Muller. Florianópolis: Fundação Boiteux/Conceito Editorial, 2006.

CAVEDON, Fernanda de Salles; VIEIRA, Ricardo Stanziola. A Política Jurídica e o Direito Socioambiental:uma contribuição para a decidibilidade dos conflitos jurídicos-ambientais. Novos Estudos Jurídicos, Itajaí, edição especial, p. 60-78, 2011.

DUGUIT, Leon. Souveraineté et liberté: leçons faites à l'Universitè Colombia, New York 1920-21. Paris: Librairie Alcan, 1922.

HABERMAS, Jürgen. O Estado nacional tem um futuro? In HABERMAS, Jürgen. A inclusão do outro - estudos de teoria política.Tradução de George Sperber, Paulo Astor Soethe e Milton Camargo Mota. 2 ed. São Paulo: Loyola, 2004. Título original: Die Einbeziehung dês Anderen- Studien zur politischen Theorie. 
HEGEL, G. W. F. Fenomenologia do Espírito. Tradução de Paulo Meneses Meneses com a colaboração de Karl-Heinz Efken e José Nogueira Machado. Petrópolis: Vozes, 2005.

HEGEL, G. W. F. Grundlinien der Philosophie des Rechts oder Naturrecht und Staatswissenschaft im Grundrisse. Frankfurt am Main: Suhrkamp, 1982 (Werke in zwanzig Bänden 7) [mit Hegels eigenhändigen Notizen und den mündlichen Zusätzen], auf der Grundlage der Werke von 1832-1845 neu edierte Ausgabe Redaktion Eva Moldenhauer und Karl Markus Michel.

HEGEL, G. W. F. Phänomenologie des Geistes. Frankfurt am Main: Suhrkamp, 1986 (Werke in zwanzig Bänden, 3) auf der Grundlage der Werke von 1832-1845 neu edierte Ausgabe, Redaktion Eva Moldenhauer und Karl Markus Michel.

HELLER, Hermann. Teoria do Estado. Tradução de Lycurgo Gomes da Motta. São Paulo : Mestre Jou,1968.

MELO, Osvaldo Ferreira de. Dicionário de Política Jurídica. Florianópolis: OAB-SC, 2000. MELO, Osvaldo Ferreira de. Fundamentos da Política Jurídica.Porto Alegre: Sergio Antonio Fabris; CPGD-UFSC, 1994.

MELO, Osvaldo Ferreira de.Temas Atuais de Política do Direito. Porto Alegre: Sergio Antonio Fabris, 1998.

OLIVIERO, Maurizio; CRUZ, Paulo Marcio. Reflexões sobre o direito transnacional, Revista Novos Estudos Jurídicos, v. 17, n. 1, p. 18-28, jan-abr 2012;

PASOLD, Cesar Luiz. Metodologia da pesquisa jurídica: teoria e prática. 11 ed. Florianópolis: Conceito Editorial; Millennium Editora, 2008.

SILVA, Ildete Regina Vale da; SOUZA, Maria Cláudia da Silva Antunes de. Fraternidade e Sustentabilidade: Conpedi Law Review, v. 4, p. 330-349, 2018.

SOARES, Josemar; CRUZ, Paulo Marcio. Critério Ético e Sustentabilidade na Sociedade Pós-Moderna: Impactos nas dimensões econômicas, transnacionais e jurídicas. Revista Novos Estudos Jurídicos, v. 17, n. 3, p. 401-418, set-dez 2012.

STAFFEN, Márcio Ricardo. Hegemonia e Direito Transnacional?, Revista Novos Estudos Jurídicos, v. 20, n.3, p. p. 1166-1187. 